\title{
Public Sociology: Working at the Interstices
}

\author{
John Gabriel • Jenny Harding • Peter Hodgkinson • \\ Liz Kelly • Alya Khan
}

Published online: 8 October 2009

(C) Springer Science + Business Media, LLC 2009

\begin{abstract}
The article examines recent debates surrounding public sociology in the context of a UK based Department of Applied Social Sciences. Three areas of work within the department form the focus of the article: violence against women and children; community-based oral history projects and health ethics teaching. The article draws on Micheal Burawoy's typology comprising public, policy, professional and critical sociology, and argues that much of the work described in the case studies more often lies somewhere in between, in the interstices, rather than within one or other of the four types. The result is not without its tensions and dilemmas, some of which are identified and explored, notably those arising from attempts to appeal to diverse audiences and meet the sometimes conflicting expectations of each.
\end{abstract}

Keywords Public sociology · Burawoy's typology Interstices $\cdot$ Violence against women \& children · Oral history · Health ethics · Department of applied social sciences · London metropolitan university

\section{Introduction}

As a group of UK based academics, we have been following the debates around public sociology, primarily emanating from the US, with great interest. The focus of much attention has been Michael Burawoy's seminal 2004 Presidential Address to the American Sociological Association (2005) and the critical responses it has since engendered (see e.g. Nichols 2007; Clawson et al. 2007; Barlow 2007). These thought provoking exchanges, including Patricia Hill Collins, view that, prior to the debate, she'd 'been doing a kind of sociology that had no name' (in Clawson et al. 2007:101) has inspired us to participate in this wider, global debate whilst seeking to 'provincialise' and capture something of the spirit of public sociology within the

J. Gabriel $(\bowtie) \cdot$ J. Harding $\cdot$ P. Hodgkinson $\cdot$ L. Kelly $・$ A. Khan

London Metropolitan University, London, UK

e-mail: j.gabriel@londonmet.ac.uk 
context of our own Department of Applied Social Sciences at London Metropolitan University.

We should begin by sketching out some key features of the University and Department. London Metropolitan University, the result of a merger of the University of North London and London Guildhall University in 2003, is one of the largest unitary universities in the UK with over 30,000 students and 1000 academic staff. It is very much part of the 'new' university sector, that has its origins in two former polytechnics that were granted university status in 1992. Our student body is diverse with over $70 \%$ mature (over 21 ) and $58 \%$ self declared as nonwhite. In 2008, the Department of Applied Social Sciences enrolled around 2500 students and employed over 90 full time academic staff. This includes over 500 part time students who are active trade unionists taking courses in health and safety and industrial relations. We have over 40 degree courses from foundation through to professional doctorates and six specialist centres in Trade Union Studies, Refugee Assessment and Guidance, Primary Health and Social Care, Policing and Community Safety, Social and Evaluation Research and Child and Woman Abuse Studies.

Michael Burawoy's view that sociology is motivated by a desire to improve society goes for many colleagues in our department, although 'improving society' means many things to many people. The latter notwithstanding, there are a number of colleagues who have consciously migrated from the old university sector and others whose careers might have advanced further had they moved to a more traditional university. For them, the scope to promote social justice at London Met. University has been of particular significance and evident in: the University's commitment to widen access to groups hitherto excluded from higher education; its support for research that consciously seeks to shape policy and enhance service delivery and, finally, the opportunities it provides to work collaboratively with marginalised communities in an ethos supportive of participatory methods and capacity building initiatives. The shape of our department reflects this wider ethos and in this sense we are not a conventional social science department, a feature which poses its own challenges, as we shall discuss below, but one that nevertheless is celebrated by the majority of colleagues.

Below are three examples of the work of the Department which can be used to address and engage with current debates surrounding pubic sociology. These include the collective work of the Child and Woman Abuse Studies Unit (CWASU), courses on health ethics and a number of community based oral history projects. Whilst divergent in terms of their content and emphasis (and partly chosen for that reason), all three areas of work share a number of characteristics.

The first is a commitment to particular values which, in common with other organizations, often remain tacit and unspoken. To this end the Department carried out a review of our 'hidden' values, such as they were (Kelly 2007). A key finding was a commitment to social justice and improvement that extended beyond the university. Using Burawoy's fourfold typology of sociology comprising professional, policy, critical and public, it is the latter mode of sociological practice deployed somewhat differently in the three case studies below, that represents an important point of reference and departure. The Child and Woman Abuse Studies Unit (CWASU), as its name suggests, is rooted in the politics of anti-violence and abuse against women and children; the oral history projects have been, in keeping with the origins and spirit of that tradition, committed to giving voice to marginalised groups (ie. young people in care, homeless 
people, refugees, immigrants). The emphasis on 'public' in the case study of health ethics teaching relates to the process of reflection in the context of knowledge production and valuation on the part of our diverse 'first public', namely our student body.

Whilst much of the department's work is thus driven by a value stance and a commitment to an albeit (and intentionally) loosely defined notion of social justice, it is by no means reducible to this value commitment. The latter may serve to define and shape the focus of activity but the research and teaching projects summarised below occupy, if anything, the interstices of Burawoy's quadrant, with some nudging more towards policy and others are more oriented towards 'public' engagement but all sharing a common commitment to learn from and contribute to the conceptual rigour and evidence base of 'professional' social science. Moreover, all three case studies elide Burawoy's distinction between instrumental (associated with policy and professional sociology) and reflexive (associated with critical and public) knowledges, so that working in both policy and professional arenas has proved at times as 'reflexive' as working in the critical and public arenas has been instrumentally driven. Whilst CWASU has been most actively engaged in the policy arena with national governments, the UN etc., it has done so selectively and strategically with the aim of influencing antiviolence policies. CWASU staff have worked with partners in the NGO sector as well as sat on committees with a view to strengthening the Unit's influence in policy terms. Taking up such positions goes beyond the kind of relationship between policy and academic elites advocated by the British Academy (2008). CWASU's external partnerships have been built over a period of time and out of strong, organic relationships forged within both public and voluntary sectors. Nor does this policy oriented, publicly engaged role preclude rigorous, evidence-based research. On the contrary, the credibility of the Unit in its relationship with policy makers depends on research that can withstand not only the scrutiny of academic peers but often sceptical and resistant professional groups e.g. the police, government officials and ministers. In the case of both the oral history projects and health ethics courses, the primary policy arena has been education (see for example Harding 2002 and Gabriel 2008), pursued with the with aim of illustrating the possibilities of a curriculum that seeks to enmesh subject benchmarks, qualifications and academic standards around priorities set by groups within civil society (e.g. patients, refugees) and, in so doing, engage diverse publics in both the development and delivery of their courses.

The 'publics', though diverse, are thus not targeted indiscriminately. In the case of the health ethics course, the primary public is the student body, which reflects the more general profile of students at London Met. University. Research evidence confirmed that whilst access to higher education has increased over the last five decades, inequalities remain, and reflect the divisions within the sector, not wholly but predominantly, reflecting the divide between pre- and post-1992 universities (Nuffield Education Seminar 2006). Consequently, the health ethics courses seek to empower students by providing them with the conceptual and reflexive skills to make decisions both in their professional and personal lives that reflect their diverse backgrounds. In the case of the oral history projects, the target publics were diverse but inevitably focused around socially excluded groups. Likewise, CWASU's projects, whilst engaging more directly in policy arenas, have also collaborated with professionals from the public and voluntary sectors and with women and children who are themselves survivors of violence and abuse. As Andrew Barlow 
argues, the development of collaborative partnerships with the NGO sector poses a number of challenges including the need to maintain legitimacy in both academic and external worlds (2007). This is all the more so when academics are themselves occupying and intervening in those public spaces as part of their wider professional role.

All three case studies also reflect the department's commitment to interdisciplinarity and interprofessional learning, since the 'publics' with whom we seek engage do not experience the finer distinctions between disciplines and are alienated by the policy specialisms imposed by statutory agencies. We seek to work with these groups as they experience the world rather than how others have divided it up. That said, we refer to all three case studies as instances of public sociology, rather than seeking a term that arguably captures a more hybrid status. Whilst this is an important area for further discussion, we choose to leave that for another time, save only that we regard sociology as a more porous discipline than most, both in its conceptual boundaries and its capacity to inform and be informed by a range of professional, public and policy-related knowledges.

Furthermore, a key feature of the work discussed below is the extent to which it builds in models of reflexive co-learning or 'public' engagement in relationship to research, curriculum development and teaching. This happens in a number of ways. Firstly the sociological canon is not regarded as significant in and of itself, but only insofar as it resonates with and supports both individual and social transformation arising out of research evidence collected from and sometimes with 'engaged' publics. In the case of the health ethics courses, mainstream philosophy rather than the sociological canon has served as a tool kit for working through ethical decisions. The latter are not only identified by the students but, given the students' diverse social and ethnic backgrounds, must be reconciled with their cultural knowledges and values. In the case of the oral history projects the pedagogic focus is on both students and wider publics but, as we remark below, these are not easily distinguished. Members of the department were part of the project steering groups as well as the training/education providers. In the case of the Refugee Community Histories Project, the participants were both 'students' and members of refugee community organisations, as well as some being refugees themselves. The oral history projects thus not only provided an exciting interplay of participants working across diverse settings but also the possibility of developing both curriculum and research data for publication within a framework aimed at engaging and empowering local refugee communities and their organisations. Part of this public engagement, in both the case of CWASU and the oral history projects, has involved public exhibitions, including one, 'Prostitution: What's Going On?' co-curated by CWASU and held at the Women's Library at London Met. and the Refugee Community Histories Project which culminated in a major award winning exhibition, 'Belonging', at Museum of London (http://www.museumoflon don.org.uk/English/EventsExhibitions/Community/Belonging/)

Such 'public' sociological practices as those described here inevitably raise an important question of credibility. As Patricia Hill-Collins suggests, for all the virtues of the debate, there are risks associated with aligning oneself to public sociology, as the critical response to Burawoy's interventions confirms (see contributions by Brint, Turner, and McLaughlin et al. in Nichols, op.cit.). Accusations of ideological bias (a common response from the profession) are bolstered by a hierarchical structure within 
the higher education sector, with its league tables based on performance criteria and a funding structure both for teaching and research which favours the older universities (Leathwood 2004). This hierarchy is echoed at the level of the academic peer group and the social capital that is accumulated there inevitably supports individual career paths unevenly. The commitment to working in and with the public undoubtedly takes time out from building relationships within professional peer groups, whilst at the same time producing knowledge that, given its origins and trajectory, is often, and perhaps inevitably, perceived as flawed from within the profession.

As Barlow reminds us the tension between academic and public pressures is one of many challenges facing what he refers to as the re-alignment of professional advocacy towards collaborative relationships across a range of diverse publics. The case studies below both serve to illustrate those challenges whilst at the same time reflecting the benefits of such engagement. In so doing they will also hopefully contribute to current debates surrounding the interplay of professional and public sociology.

\section{Oral History Projects_-Jenny Harding}

Michael Burawoy wrote that 'the challenge of public sociology is to engage multiple publics in multiple ways' (Burawoy 2005, 4). He went on to say that 'public sociology brings sociology into conversation with publics, understood as people who are themselves involved in conversation. It entails, therefore, a double conversation' (Burawoy 2005, 7). But, what kind of conversations are sociologists to have, and with what kinds of publics? What are such conversations for and might they achieve? Publics are not static and fixed but are multiple and fluid. Moreover, sociologists can 'participate in their creation as well as their transformation' (Burawoy 2005, 8). Contrary to some commentators (Scott 2005) on this side of the Atlantic who were sceptical and even daunted by this claim, our projects seem to confirm Burawoy's critical observation.

Burawoy also distinguished between traditional and organic public sociology. The traditional public sociologist investigates debates within or between publics, but might not actually take part in them. The organic public sociologist works 'in close connection with a visible, thick, active, local and often counterpublic' (Burawoy 2005, 7). Public sociology tends to be inter-disciplinary and seeks to develop reflexive knowledge. Once again, our experience, as recounted below, tends to support this characterisation.

Here, I discuss how three interdisciplinary projects, ones that might now be considered examples of what Burawoy calls 'organic public sociology', sought to engage multiple publics in a number of ways; how they 'took sides' and, in doing so, created both publics and conversations. These projects also involved elements of 'critical sociology' in so far as they were necessarily engaged in a politicised process of empowerment and persuasion. Each project involved life history interviewing and was framed by a commitment to highlighting everyday, subjective experience and thereby 'giving voice' to marginalised groups as part of a process of empowerment ${ }^{1}$.

\footnotetext{
${ }^{1}$ The empowerment of 'disenfranchised' groups has been an enduring and dominant theme in life story research since the 1960s (Stuart 1994; Perks and Thomson 1998; Thompson 2000).
} 
Each project was also informed by pedagogic and theoretical commitments which encouraged critical reflection on the research process itself and made explicit the power relations involved.

\section{Care Stories}

We were invited by community-based professionals in social work and family therapy to apply a previously developed model integrating research and teaching (Harding 2002) into the production of a film representing the emotional needs of young people in foster care. This resonated with contemporary conversations in Higher Education sector regarding work-based learning and, in particular, about 'student volunteering' (service learning) as a way of promoting active citizenship and employment opportunities for students whilst, at the same time, improving the quality of life in disadvantaged communities (Harding and Gabriel 2004). We responded by designing a project and successful bid to the Higher Education Active Community Fund, which provided support for learning through volunteering. Care Stories involved university students studying Oral History and Digital Media in interviewing young people about their experiences of foster care and making a film to train people providing professional services to 'looked after' young people.

The scope and design of the project evolved through a series of meetings involving staff from community-based organisations (family therapists, social workers, youth workers), staff and students from the university, and young people in the process of leaving care ${ }^{2}$. 'Being listened to' was a dominant theme in the project's design and implementation and great emphasis was placed on enabling the young care leavers to communicate what mattered most to them about their experiences; that is, what others should know about being in care, what worked for them and what could have been better. To this end, we facilitated conversations between staff and students, and students and young people, which helped to create a context for the project and rapport between young people as interviewers and interviewees ${ }^{3}$. Students were trained in interviewing techniques aimed to facilitate the interviewee talking at length and in detail about topics that concerned him/ her, using his /her own terms and reference points. A twenty-minute film was produced from over twelve hours of videoed interviews, organised around the themes that had emerged in the conversations between interviewers and interviewees ${ }^{4}$. The film has since been presented at conferences on the emotional needs of looked after children. A second film and booklet have been produced which contextualise the project and, together with the original video, these have been widely used in professional training.

\section{Family Matters}

The starting point for the Family Matters project was a conference at Oxford House, in the London Borough of Tower Hamlets in Somali Week, 2006. The conference

\footnotetext{
${ }^{2}$ For detailed reflections on the project process, relationships involved, methodology, and the student learning experience see earlier papers by Harding and Gabriel (2004) and Harding (2006).

${ }^{3}$ Participants - seven care leavers and eight students - were all self selected.

${ }^{4}$ Young people were involved in the process of planning interviews and, although they did not participate in the editing process, they viewed the edited video and approved it before it was shown to professionals.
} 
debated a range of issues facing Somali young people - in particular, possible barriers to participation in society and intergenerational conflict. Many concerns expressed by young people focused on cultural tensions between themselves, their parents and community leaders. Somali young people reported difficulties in accommodating their parents' views with their own desires to become active and independent participants in mainstream UK society.

We were invited to develop a project in partnership with LB Tower Hamlets, Oxford House Youth Project and Arts Aimhigher. Our role was to design and supervise exploration of intergenerational issues through focus group and one-to-one interviews led by Somali fieldworkers with young Somalis and their parents, and write a report based on analysis of interview transcripts. The interview transcripts and report were used as the basis for writing a new play, created by two Somali writers and a British director, called Too Close For Comfort. The report was publicly presented and the play performed during Somali week at the end of October 2007. Audiences were invited to discuss both the report and the play. A film version of the play was later produced for use with the report and script as a learning resource.

\section{The Refugee Communities History Project}

The Refugee Communities History Project was an oral history project, which, between 2004 and 2006, collected, archived and disseminated 164 life story interviews with refugees who came to Britain in the period since 1951. The project was initiated and managed by the Evelyn Oldfield Unit, a refugee-led organisation, which provides support for refugee community organisations (RCOs), in partnership with the Museum of London, London Metropolitan University and fifteen RCOs. The Evelyn Oldfield Unit and its member RCOs first conceived the project as a response to what they perceived as a sustained media attack against refugees, and as a way of engaging the public in understanding and empathising with the experiences, views and concerns of refugees as expressed by refugees themselves.

The RCHP set out to document the contributions made by refugee communities to recent history of London and to promote diversity and inclusiveness within the city. In other words, the project aimed to make an intervention in cultural politics and empower refugee communities by enabling them to produce alternative narratives of their lived experience.

We were invited to work on this project between 1999 and 2007 as members of the project steering group (involved in project design, planning, and fund raising) and as the project partners responsible for training fieldworkers to interview and disseminate the content of interviews via a range of media. Fieldworkers worked with university staff and members of their communities to produce community based outputsresulting in a total of eleven films, four CD-Roms, ten exhibitions, one art installation and fifteen community events (Day et al. 2008). A major exhibition, Belonging: the voices of London's refugees, was held at the museum of London in 2006.

\section{History and Context}

Our participation in the projects discussed here is an outcome of earlier oral history projects also involving students as interviewers as part of regular teaching and 
learning at London Met (Harding 2002 and Harding and Gabriel 2004). This pedagogic approach developed in response to the demography of the student bodydiverse and disadvantaged - and as a way of engaging students in reflecting on their own subjective experience and participating directly in knowledge production. The position of the university - as a subaltern/post 92 institution with a commitment to serving the local community - has meant that academics may exercise a degree of creativity/autonomy in looking beyond fellow academics and research councils for partnership and funding. In conducting oral history projects, we have formed partnerships with a range of local organisations - refugee community organisations, museum, social services, a mental health facility, a centre for homeless people - and received funding to promote heritage, student volunteering, and community development. These partnerships have been very positive and productive, though not without tensions. Tensions sometimes arose between a tendency among some community based groups to view oral history narratives as spontaneously articulated and our tendency as academics to repeatedly pose sociological questions about methodology and foundational (to oral history) concepts such as empowerment, community and identity.

\section{Sociology and Publics}

With their focus on community-based research and 'subaltern knowledges' (Burawoy 2005, 18), these projects enacted a kind of organic public sociology. They enabled us to engage in multiple conversations with, and help to create and transform, multiple publics: first, students engaged in work-based learning as interviewers; second, professionals from community-based organisations; third, a number of marginalised groups; and last, numerous diverse audiences who respond to various media outputs from these projects. But, life history projects bring limitations as well as possibilities, threatening to close down as much as open up 'the public'.

The life history projects discussed here attempted to speak to, and for, specific publics and, in doing so, traced a boundary constituting and anchoring these publics, giving the impression that they already existed and were fixed rather than contingent and provisional, so precluding the definition of other possible publics. That is to say, the projects helped to 'make' the communities and experiences they sought to represent through their design, selection of interviewees, interview process and relationship, interpretation of the interview material, and its representation in papers, reports, videos, exhibitions etc. Further, in attempting to represent experiences of marginal groups, they tended to homogenise, essentialise, normalise, and simplify their experiences and identities, and sometimes excluding others.

Whilst oral history projects tend to aim to empower by 'giving voice', empowerment, in our experience, is a relative term constrained by available resources and, in particular, the relations (of power) constituting the research process (Harding and Gabriel 2004). Empowerment through interview has to be understood, not as a single act leading to a reversal of fortune, but as always partial and "part of an ongoing process of self reflexivity, production and transformation within the research encounter and hegemonic relations which constitute it' (Harding 2006). 
The generation of life histories and their impact need to be understood in their social and historical context. They are always collaborative and co-produced and variously influenced by circumstances and feelings of the moment, that is, 'concerned with the present and subjectivity as much as fact and the past' (Harding 2006). For example, we heard through informal feedback that professional audiences viewing the film Care Stories were surprised at the frankness and openness of interviewees' narratives, which they felt would never be have been related to professionals. This might indicate a willingness on the part of young care leavers to critically reflect on, and speak publicly about, their personal experiences of foster care on the grounds that this might 'make a difference' to others, maybe more typical of their generation than older generations, and a considerable degree of warmth and chemistry in conversations between interviewers and interviewees (Harding and Gabriel 2004).

\section{Impact}

What impact have these projects had and on whom? There was no systematic attempt to evaluate the impact of Care Stories (videos and booklet) on professional audiences but over 200 copies have been requested by local authorities and private fostering agencies and we have been informed (by family therapy colleagues involved in dissemination) that they are widely used in training and always well received. We were told by a colleague at the Tavistock Portman NHS Trust 'we continue to use it in training here and its still has considerable impact.'

Belonging: the voices of London's refugees, an exhibition at the Museum of London and a major outcome of the RCHP, was evaluated by an external evaluator, who conducted an in-depth summative evaluation project, using tracking, exit interviews and focus groups. The exhibition ran for 4 months and was visited by more than 32,000 people. The evaluation report concluded that,

'Participants across all the visitor groups described the exhibition as important, emotional, informative, and as giving a voice.... It is rare, as a visitor researcher, to encounter such engagement and impact during and as the result of one single experience of an exhibition. This is unique and extraordinary and shows the power of museums to move, engage, educate and inspire into action...' (Johnsson 2007, 58).

If, as Burawoy argues, recent interest in public sociology is partly a response to the 'privatization of everything' $(2005,7)$, then our task as sociologists must be sure not only record the trauma and difficulty in lived experience but also to contextualise and historicise it. That is, we must insist on recognising the relations of power and inequality that produce subjective experience. In this respect, we feel these projects are an attempt to publicise both the creation and valuation of hitherto privatised knowledges.

\section{Child And Woman Abuse Studies Unit- Liz Kelly}

CWASU was founded in 1987 by two social work lecturers in what was then the Polytechnic of North London. From the outset it took an unapologetic feminist 
stance seeking to develop - through research, training - theory and practice on child sexual abuse. As social work training and education looked increasingly to the professional body and the public sector, CWASU looked towards the NGO and the policy sectors. This was one feature of the Unit's development that provided some measure of independence within our institution. The other was the university's willingness to support policy engaged research even at the expense of a reputation built on more conventional publications-led outputs. Of course a key to our 'being left alone' has been our successful track record in attracting external funding and the fact that we have built a reputation which has straddled the academic/policy divide. Over two decades we have extended our focus to all forms of violence against women, and have a national and international reputation for our work, which includes 90 projects (see www.cwasu.org.uk for more details). We can claim to have had a number of 'successes', in changing perception and influencing policy development.

Like Patricia Hill Collins, for us the development of public sociology as a field gives formal recognition to ways we have 'done' sociology since our inception. It is challenging to bring into the language of the academy ways of working which have developed organically in our 'doing' of feminist research.

Whist Burawoy's four dimensions of sociology are a useful heuristic device, our practice sits 'in between' the four, as well as in between the academy, policy and practice. These spaces 'in between' are simultaneously creative and productive and lonely and isolating. Concerns that naming public sociology may result in the ghettoisation of those who espouse it are not groundless. Occupying multiple locations means never really being embedded and embraced within any of them, since you rarely fulfil the requirements of any of the publics engaged with. One is not theoretical or respectful enough of the academic, too critical and/or aspirational for the pragmatism of policy, not critical enough in choosing to engage with government and policy makers directly and in person in the hope of affecting change in current lived realities, and are too complex and thoughtful for journalists and practitioners. But there are times when working 'in between' offers possibilities for connection and influence that make the being everywhere and nowhere worthwhile.

Before exploring how the work of CWASU traverses Burawoy's modes of sociology there are two aspects of the debate that require further comment. Burawoy himself talks of the necessity of 'conversations' with publics. This is an apt analogy/ description for work which involves the mind and words, but other analogies offer additional ways of reflecting on what we are doing. In describing our own work, and that of feminists more generally, we have used the metaphors of dancing and embroidery. Feminist researchers and organisations who engage with governments can be seen as 'dancing with state', and the dance can be slow and ponderous full of mis-steps or at other times involving such rapid movement that it is hard to keep pace. The embroidery analogy extends ideas of quilt making, often a collective project. Embroidery requires time and patience, every stitch counts, it requires many colours, different threads and stitches - and as anyone familiar with needlework knows sometimes you have to unpick a section and begin again-but with the knowledge of what was not right the first time.

The second issue is that engagement with publics as sociologists is invariably discussed as if we are not part of any them. Whilst our own discipline is one such 
public of which we are all part, many of us are also connected to social movements in which we are not outsiders looking in, but insiders who have played a part in shaping directions of travel. The women's movement is a particular public, of considerable dimensions - it is argumentative with local, national and global components, an extraordinary diverse public engaged at all levels of social life and civil society. Burawoy's 'organic public sociology' is seen primarily as sociologists 'working with a visible, thick, local and often counterpublic' (Burawoy, p28), not being within such publics. Insider knowledge is both an advantage and a potential limitation. Working in between as we understand it involves having one foot outside the publics we are part of, enabling critical reflection on how divisiveness and fragmentations in civil society are structured and reproduced. The reflexivity demands here are considerable - reflexivity about self in movement.

\section{CWASU and the Four Sociologies}

\section{Professional Sociology}

Professional sociology is a foundation for all of us, as our disciplinary location. For CWASU working with concepts has always been a core part of our engagement, but the location of 'in between' places a requirement for engagement, working with concepts in ways which make them accessible for other publics. This demands ways of thinking/ describing that encapsulate questioning tacit knowledge and communicating with a preference for simplified perspectives, rather than the 'its more complicated than that' messages of social science. This is something more than what Sally Merry (2007) calls 'translation into the vernacular', which seeks to make existing knowledge/frameworks (in her case study human rights) accessible to diverse publics; what we refer to here is a weaving of concepts into the way we write up our research data which offer new ways of thinking, and new routes to exploring complexity.

We have also never been afraid of questioning orthodoxies, including within feminism. When we began there was a strong strand of thinking and writing on feminist research, which asserted it was 'on women, for women, by women' and that 'feminist methods' were qualitative (see Kelly et al. 1994 for more detailed discussion of this). We broke all these rules, and argued that feminism provides a theoretical framework, with methods as tools which are combined to explore specific research questions; rather than a feminist methodology we argue for a feminist research practice, which requires humility, respect and rigour.

\section{Policy Sociology}

We appreciate Alan Touraine's comment that 'public sociology combines more easily critical thought with good empirical studies'. This is our ambition, articulated in a slightly different way by Liz Stanley:

... feminism outside of the academic mode has insisted on the crucial need for useful knowledge, theory and research as practice, on committed understanding as a form of praxis ('understand the world and then change it'), and also on unalienated knowledge (1990, p12). 
Burawoy's definition of policy sociology is that its goal is defined by clients rather than the researcher, but the terms of engagement are rarely so limited, and we all make decisions about which contracts to bid for; making such decisions through our arenas of interest and integrity as an academics/researchers. Many policy makers are interested in knowing about complexity, and some contracts offer the real possibility to make contributions to knowledge. One of our publics is feminists, who can be located in many unlikely places. We have taken several small contracts designed by individuals to enable us to provide a gender perspective on current issues.

There is also the question of who the client is - is it only funders? There has to be an argument that those who participate in research are publics to whom we have responsibilities. In our research practice we endeavour not just to give voice, but to develop in our methods spaces for reflection for those who take part.

Policy research, and becoming a respected research unit, enables us to get closer to the state-witnessing its workings up close and personal. Keeping a place at table requires demonstrating trust worthiness, whilst contributing a critical voice rooted in respect for those who take part in our research. Working with this public is fraught with dangers, but also offers the potential of influencing public policy in a more immediate way. We see our responsibility to those who participate in our research projects as advocating for understandings, policies and practices which more accurately reflect the realities and complexities of their experiences.

In wanting to move forward with issues - whether it be at the level of policy or theory - there is a temptation to forget the basics; but several of our recent projects reveal that it is precisely these basics which matter most to children and women (at the same time as they reveal some of the core dynamics in interpersonal violence). The inputs from workers and agencies which children and women consistently report mattering most to them are: that someone named what was happening/had happened to them as violence/abuse; a clear message that it was not their fault; that abuse is the responsibility of the abuser; being told and believing they were not alone; and being told and thus being able to feel that they deserved something better.

\section{Critical Sociology}

In terms of values we have always worked from an unapologetic feminist perspective, which has had a strong intersectional component. But our critical engagements are both within sociology and feminism - returning to issues from new and emerging positions. For example, feminists and women's organisations were (and continue to be) extremely sceptical of perpetrator programmes. Evaluating several (see, for example, Burton et al. 1998) led us to a rather different position. Not because they succeed in transforming the men who participate, but because they gave women a route to locating the problem with their male partner. Listening to how women described insisting their partner's attended, and the power being able to name the problem as his, led us to re-think the place of such programmes in responses to domestic violence. This in turn led to several training days with women's organisations, crafted around explorations of what counts as success, and how women might use such programmes to re-negotiate power, including the power to define. 
Another example here has been our critique of the rehabilitation of the concept of 'paedophile' (Kelly 1996), on the grounds of meaning, in that its literal definition-'lover of children'-is diametrically opposed to its use with respect to sexual abuse. More importantly, however, this shift in public discourse has served to detract from the emerging understanding that most abusers were known to the children, part of their social networks, rather than 'deviant strangers'.

We do not expect publics with whom we engage to be steeped in critical social science, neither do we assume that discourse will remain unaltered through processes of engagement. Our approach is a constant iteration between our core values (we are reminded of these by key allies in the NGO sector) and new evidence generated through research. As researchers our aim has been to generate spaces in which we use theory and concepts to enable others to reflect on, make sense of and ultimately to transcend the present; this contrasts to some uses of theory where action is yoked into an all embracing explanation or taxonomy. Our conscious shift away from the purely academic has enabled us to engage in a different kind of social science, one that deploys concepts (critical or otherwise) in the practice of policy engaged research: sometimes the external conditions call for an oppositional stance, at others such a position may be taken indirectly and implicitly, and in some circumstances we may choose conscious omission of an overtly critical voice. These are the judgement calls public sociologists must make if they are interested in their work having practical application/relevance in current policy debates. We are also increasingly aware that strong data often speaks for itself, and can even be undermined by the use of an ideological trowel. Change, the requirement for any movement towards social justice, is messy, political and fraught with compromise. Discourses that appear helpful in one conjuncture appear less so in another

\section{Public Sociology}

In CWASU we engage with multiple publics, and offer a few examples here of how we use research and concepts in these processes.

- The training and speaking which we currently undertake spans basic awareness through to working with women's organisations to explore difficult and complex issues. From the outset training has been seen as 'thinking time': not offering skills or models, but the space to explore and reflect on the interface between research and practice. Our exercises are designed to enable contained questioning of emotive issues, and invite engagement with new approaches. This has been, in recent years, extended to an MA, which we designed to encourage practitioners in the voluntary sector to take time to think and explore new perspectives and new research.

- We speak far more often at practitioner and NGO conferences than we do at academic ones. We have prioritised these publics as the ones most able to decide whether the knowledge we produce is useful, and how it might be used. Informed and knowledgeable practitioners and policy makers are not impressed by 'clevering on', but by relevance and the recognition by academics that theory and practice are in complex connection. In our experience questions from 
practitioners often demand more reflexivity and adaption of perspective than those from fellow academics.

- We also use writing, speaking and training to make connections - between forms of violence against women and between child and woman abuse. This is one of the most important contributions the CWASU has, and continues to make. Here our links with international policy makers in the UN and Council of Europe have been fruitful and demanding.

- Michael Burawoy refers to journalists as a particular public, and here again we have developed a particular practice. Rather than provide soundbites and/or get our names in print, we have sought to engage in conversations in which we attempt to re-frame the question/debate. This requires time and patience-both of which can be in short supply! With this public one has to find ways of expressing complex positions in terms which journalists can not only 'get' themselves but present for a mass audience. Some of the interventions we are most proud of here are not attributed to us. Just two examples will suffice. In the mid-1990s we spent time talking with researchers from one of the most respected news comment programmes 'Newsnight' on the issue of child pornography. The central idea in their feature was one we provided - that these are not just images, but records of abuse. This was to become a new way of thinking about and responding to the issue amongst children's rights organisations and the police. More recently we spent many hours talking with the writers and producers of what would become an award winning drama feature on trafficking. Their willingness to represent the complexity of many women's decision-making and situations led to a more nuanced representation.

- The legal system is another public, and we have provided expert opinions for criminal and civil legal cases. In contrast to the medical model of expert evidence, which seeks to demonstrate the individuality and difference of the person, our practice has been to develop an approach which maps out the relevant research knowledge, and seeks to fit individual women's lives into this broader picture. We thus locate women within a social context.

- Some of our recent writing and research has been for a coalition-the End Violence Against Women campaign. Having drafts read and commented on by twenty or more knowledgeable practitioners changes how you write the original text, and its revisions. This is considerably more demanding, engaged and nuanced than most peer review processes, and requires more than a little humility about what one does not know and whether one's ideas have relevance beyond the academy.

These examples are not 'pop' sociology, but committed attempts to communicate across boundaries, to stand in between.

\section{Health Ethics- Alya Khan}

Recent debates within academic circles about the idea of public sociology and the concurrent identification of the public sociologist have fore-grounded discussions about the appropriate boundaries of the sociological community and the role of sociologists, and perhaps all social scientists, in public life. Most significantly, the 
notion that a truly 'public' sociology ought to seek to engage various 'publics' in 'dialogue' rather than somehow studying society 'from the outside' has received much scholarly attention. While this cannot be said to be an entirely new idea, it may be interesting to explore its formulation in this current context, and to think about the possibilities that its theoretical development may produce for social justice today.

My intention here is to begin to explore the idea that public sociology may be a dialogic and relational activity that somehow involves the engagement of the purportedly 'expert' community of social theorists (academics, professional sociologists, independent scholars) with various publics, in acts of social transformation. It would be interesting to consider whether or not this is the case, and if it is, precisely what might constitute this particular form of relational and dialogic activity. But my aim here is more modest. I will give a description of my experiences of teaching health-related ethics within an applied social sciences university department, and will reflect on whether and in what sense this activity may count as public sociology in the context of current debates. Rather than analysing the descriptive content of the concept of 'public sociology', I am going to see whether I can pick out in the world an instance of what has recently been named 'public sociology'. I am doing this for practical reasons, most importantly to reflect on, and share my thoughts about, my own practice, and to participate in the debate.

The naming of public sociology may mean that practices hitherto unacknowledged or misrecognised in the discipline are being given weight and value, and I am interested to see if and where my work fits in this newly defined space. But I am also slightly cautious for it might be the case that being aligned with public sociology as it is currently conceptualised situates practices within a certain bounded and therefore limited (and limiting) sphere. My aim is to be always open to new possibilities for progressive social change, and it is with this in mind that I traverse the new public sociology terrain, adding my analysis to the mix.

My intuition is to agree with those theorists who suggest that public sociology involves the application of social theory and the methods of social philosophy in a specific, public, way, to the everyday dilemmas and social issues that seem to matter most (or are taken to be most pressing) within civil society in a given place and at a given moment. My hunch is that public sociology is best understood as a localised activity, with potential ramifications for wider society (perhaps through the generation of widespread public debate), but with greatest initial effect and most significant impact on the publics with which it engages within a particular time and place. This seems to fit with Burawoy's description of the work of "organic public sociologists who engage directly with specific, local publics that are thick and active," (Burawoy 2008, p.2).

I will describe here what I think can be construed as an example of Burawoy's 'organic public sociology' that comes from my interpretation of my own experience. This interpretation rests on my own reasons, and its authority is thereby constitutive. But it connects with views Burawoy and others hold about what it is to be doing public sociology, and exploring these connections may be fruitful.

I am interested in the idea that teaching in a certain student-centred way constitutes the deployment of social theory in a public context, at once inside and outside academia, and that this is what is meant by organic public sociology. My propositions are that students (for example the ones who take my health ethics classes) can be seen as a particular public group with whom public sociologists can 
engage; and, that the critical pedagogy $y^{5}$ that I employ in the classes that I teach is a particular form of dialogic and relational engagement with a particular public that may count as doing organic public sociology.

Burawoy speaks of:

"constituting students as a potential public, engaging with them as a community with pre-existing experience that they bring into the classroom.

Teaching turns this community into a public..." (Burawoy 2008).

I agree that this can occur, and where this is consciously facilitated, I am interested in if it can be harnessed in ways that may be beneficial to the particular community, and perhaps beyond.

Students initially stand at what has traditionally been seen as the boundary between academia and non-academia, reaching in to share and learn from what is there, perhaps hoping to find tools to use in their own lives, but also bringing with them opinions, beliefs and standpoints from outside the university that may challenge, contribute to and possibly deepen and transform, ways of doing academic work in the social sciences. The ideal is that this is a relational engagement, a participatory and inclusive activity between intersecting (and I think overlapping) communities, where experiences are articulated, beliefs are shared and debated, needs are identified, and valuable theoretical and social transformations may ensue. Dialogues between social theorists (as teachers) and students (as a specific public) may have the potential to be mutually beneficial. And where they extend beyond the academy, they may benefit wider society.

As a philosopher by academic background, I am committed to rigorous and critical conceptual inquiry. As a teacher, I am committed to developing a critical pedagogy with the potential to empower students and lead to progressive social change. I view my various practices in both research and teaching as complementary toward the goal of contributing to social improvement, and find myself in a department that welcomes and supports the kind of work I do. Interdisciplinarity is fostered within it; different disciplinary practices can be brought together, within the context of broadly shared (although constantly debated) values of social justice ${ }^{6}$. For my own part, I contribute to the department by working with students studying social sciences applied in the area of health, where I bring the possibility of engaging in explicitly philosophical activity around ethics and values.

Teaching students the skills of philosophical and critical thinking and facilitating their abilities to locate, grasp and draw on normative ethical theory when developing, articulating, and justifying their own ethical views, can I think be seen as a way of connecting with a public, a particular community of students, who have approached and are in close relation with the professional academic community. In

\footnotetext{
${ }^{5}$ By critical pedagogy I mean a style of teaching and learning that involves a certain reflexive attitude, one that requires those involved to be committed to exploring the curriculum and their own response to it with the dual aim of identifying operations of power and rectifying processes of oppression therein. (N.B. I have found Paolo Freire's Pedagogy of the Oppressed, 1970, and bell hooks', Teaching to Transgress, 1994, invaluable as I have reflected on the development of my teaching practice over time).

${ }^{6}$ Within the department (DASS) I see rich and deep enquiry and debate regarding the concepts and conceptualisations of, e.g., freedom, democracy, citizenship, equality, justice, human rights, etc. But there is an overarching sense that colleagues are committed to a broadly progressive, egalitarian, social agenda.
} 
my practice, however, I aim to extend pedagogy to include not only pointing students in various directions that enable an academic perspective, but also developing amongst them a community of enquiry into health-related ethical issues, especially ones that they say matter to them.

From the outset students on the applied health ethics courses are introduced to the idea that they might see themselves as members of a learning community, working together with the shared purpose of critical enquiry into philosophical ethics and its application in health-related contexts. They are introduced to plural ethical approaches (e.g. principled approaches; narrative approaches) and to normative ethical theories from within the canon (e.g. deontology, utilitarianism, virtue ethics, feminist care ethics, situation ethics), all of which may be applied to resolving ethical dilemmas in healthcare. Their knowledge and understanding of these is formally assessed in ways that measure up to the required university and external examiner standards. At the same time, however, a learning environment is created that facilitates their development of their own personal preferred means of ethical deliberation and judgment in relation to healthcare, and throughout the courses an emphasis is placed on students developing their own ethical ideas, their own meanings, and becoming independent critical thinkers. As a community of enquiry, students spend much time in discussion. Normative theories are presented for scrutiny-what do we think of them? Do we agree with them? How useful or relevant are they for us? The precise ways in which some of them are embodied in the public institution of healthcare are highlighted, and students consider if this needs to be modified to fit with their beliefs about what ought to be our contemporary public values in health.

My own academic standpoint as a philosopher interested in moral, social and political theory, including questions about social epistemologies, the production of knowledges and knowers, and the application of theory in practice, informs my approach to teaching; but so, too, does my own social experience, and it is as a social being with a social identity that I find students relate to and engage with me in a community of enquiry. We stand together, interrogating concepts, considering our own beliefs, developing a capacity for critique. This requires a certain reflexive attitude on my part, where I am at once imparting academic techniques and knowledges, yet also participating directly in enquiry alongside students. Here, I appreciate Patricia Hill-Collins' conceptualisation of what has been called a kind of dual intellectual citizenship (Hill-Collins (2000)), where the work of a critically oriented teacher may involve being able to draw on academic methods and knowledges, while at the same time being able to 'see the world' from students' perspectives - perhaps especially so where both teacher and student have similar experiences of social disadvantage, but possible anyway where there is shared purpose. I, too, then am constituted as a member of the particular public - I am within the community ${ }^{7}$.

The students work with a variety of contemporary ethical dilemmas relating to health. They can select dilemmas from the literature, but are also given the option to bring their own dilemmas, from their own experiences, or from situations they have

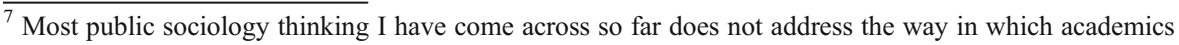
or professional sociologists, etc. are themselves constituted as publics, and the implications of this.
} 
read about or seen in the media. For example, many students in the most recent cohort have been interested in the rightness or wrongness of euthanasia, having seen news items dealing with the lives of individuals seeking assistance to die. Others have followed high-profile public debates about the ethics of genetic counselling, access to safe abortion (including the ethics of the UK conscience clause for doctors), the allocation of resources in healthcare, and the implications of the recent UK Mental Capacity Act (2005) for patient autonomy. Many are particularly interested in thinking about how different cultural perspectives are addressed in mainstream healthcare policy and practice in the UK, and how religious reasons for agreeing or disagreeing with certain treatments and techniques fit within supposedly universal ethical frameworks.

Some work in healthcare settings and bring dilemmas from their professional lives, others describe intensely personal experiences. In this way, they identify and deal with what is important or stands out as worth addressing to them. This fits with current ideas about the scope of public sociology, and brings to my attention their specific needs and interests with respect to values in healthcare. They explore the relationship between their personal ethical views and what may be their public and/ or professional responsibilities in health-related settings, and discuss how these might be negotiated where they conflict. They are encouraged to look for what the disagreement precisely is and where there may be agreement or the possibility for compromise or arriving at consensus. But the discussion is open-ended-the aim is not necessarily to reach a unified position, but to participate in an ongoing association for the duration of the class, across differences.

As well as essay-writing, assessment of learning also involves students doing presentations on health ethical dilemmas, and this can take the form of role-play where students may present their own standpoint or consider the standpoint of others through re-enacting a narrative. The latter often results in them realising mistaken assumptions they have made about the views and experiences of others, and reconsidering their judgments. This technique also often raises the level of student engagement with abstract ethical theory as they apply it to their dilemmas and consider its practical efficacy. Their confidence as critical thinkers about difficult ethical dilemmas often grows markedly; classes are lively; and, though they are challenged and may find it hard going, students often report how much they get out of the sessions. The quality of their assessed work reflects their achievement.

The student body at London Metropolitan University is diverse in terms of background, situation and experience, but also in terms of epistemological standpoints. Students hold a variety of different views about ethics and morality, often stemming from different social, cultural, religious or secular perspectives, approaches, experiences or habits. A relatively high percentage of students are members of marginalised and disadvantaged social groups, where a sense of disconnectedness from public debate may hamper confidence in what they are asked to do in class. Some students begin their studies with strong, personal opinions about the ethical issues on the syllabus, and are disinclined to query them. This can create conflict and discomfort during discussion sessions; but in teaching I aim to be responsive to the specific situation of each particular group of students and to foster a sense of community and shared purpose in study. Hierarchies and power struggles can and do emerge at times in these diverse groups; my intention is to be aware of 
and diffuse these wherever possible by drawing attention to the focus of the group on the activity of shared inquiry. Our starting point is the question "what should be done?" If we can bear in mind that we are inquiring with a shared purpose, then we can view disagreements as part of the inquiry, and create a space for negotiations across difference. Within these inevitably heterogeneous student groups, misunderstandings and tensions can arise - but it is my overriding experience that students can and do engage in difficult dialogues about health ethics, with outcomes that significant numbers of them value. For example, a student wrote about her experience on a course evaluation form that "We don't always agree in class discussions - but this didn't matter and we were all able to join in with our different views. It really helped me get my own view straight. " Clarifying for themselves and voicing to others their own views, especially their needs and values with respect to health, have been important to many of my students.

In addition, students often let me know on an informal basis what they think about the courses and what they believe they are getting out of them. This feedback usually occurs in the classroom, or during breaks or at other times. It supplies me with information about how I might best develop future sessions, and also forms part of a critical engagement that goes beyond the formal structures of the classroom. Students sometimes thank me, which surprised me at first, but now I see that they are thankful for being directed towards theory and ways of approaching ethical dilemmas that they feel able to apply not only in their studies but also in other aspects of their lives.

As students engage with theory, their critical and analytic skills develop; as they engage with each other across different ethical perspectives in open but purposive enquiry they have the opportunity to work out and defend their own values and beliefs, in part through actively listening to and considering the views of others. They are introduced to Socratic dialoguing, and to methods of systematic, rigorous and critical thinking. Many find working in this way to be personally empowering, as they learn to critique standard views and to articulate and support their own perspectives. They develop ways to argue for and give 'voice' to the way they see things.

But what effect might the sort of critical engaged pedagogy I have been describing have on the world outside the university? Does teaching applied ethics in this way really fit any definition of 'public sociology'? Does it reach out beyond the boundaries of the academic institution to work with communities towards defining and aiming for social justice? It seems to fit well with Burawoy's notion of 'teaching as public sociology', where students are engaged in dialogue with teachers, and also with each other. There is, however, a third type of dialogue envisaged by Burawoy, one that involves "students as a public among other publics" (Burawoy 2008, p.6), where students, in becoming aware of themselves as a public, "somehow try to involve others in what they have learned at the university" (Burawoy 2008).

My thoughts are that in fostering the capacities for critical ethical decisionmaking and social responsibility with respect to healthcare within a diverse student community made up of individuals who inevitably are actors in and on society, what occurs in the classroom must impact on the wider social world. I have, at present, only anecdotal evidence of this - students tell me, while doing the courses, or after they have completed them, how they take their learning to their homes, their 
workplaces, their communities beyond the university. There is scope, perhaps, for research in this area, especially where students (as some do) go on to roles in healthcare, health policy-making, health management, volunteer, or communitybased work in health, or sitting on health-related ethics committees. Some will have professional responsibilities for developing procedures that will affect the health experiences of large populations. It would be interesting to evaluate the relation between their experiences of the classes and their later practices.

For now, however, I am claiming that in working within an inclusive community of learners towards developing and exercising critical voices, ones that work out, express and argue for what they take to be just in relation to health, students can and do grow as responsible citizens and figure out ways to act well in a shared world. They can take their critical and analytic tools, gathered in the classroom, out into the other public spaces they inhabit beyond the institution, and they can continue working with them there. These things are not, of course, guaranteed-individuals may reject the idea of working for the kind of associating across difference with the aim of developing a common purpose that I am espousing. But in opening up spaces within the classroom where students have dedicated opportunities to view and discuss the world, their lives, their ethical choices, in a different way, new ideas may be thrown up and new practices envisaged. For some, there may be mutual recognition across difference, and an understanding of the potentials for justice of continued, public, open-ended dialogue.

\section{Conclusions}

The article has attempted to provide three instances of public sociology, each located somewhere in the interstices of Michael Burawoy's quadrant, and each and collectively engaging with diverse 'publics'. In all three cases the authors positioned themselves ambiguously in relation to those 'publics'. Alya Khan drew on the notion of dual intellectual citizenship to characterise her role, both co-learning with her students whilst at the same time enabling them to develop reflexive understandings of ethical philosophy and its application to health care settings. Liz Kelly positioned CWASU between rather than within the boundaries of each of Burawoy's four sociologies so that CWASU's critical feminist stance has been harnessed to a professional role (exercised through rigorous, evidence based research) that in turn is used to inform and support the NGO /public sector as well as influencing change at a policy level. Jenny Harding's oral history projects worked across the academic and community sectors with a strong emphasis on using education as a tool for community development and empowerment.

There are many ways of practicing organic public sociology and the three case studies above are illustrative of some of the possibilities here. In the case of health ethics, Alya Khan was working both inside and outside the academy, developing a community of enquiry with students whose worlds also straddled both. The multiple identities beyond those of simply academic and student, provided further opportunities for engaging on the basis of commonalities and difference. Liz Kelly and Unit staff were also working both inside the academy but also outside as part of 
a wider women's movement, and not as detached observers but on the contrary helping to shape the direction of travel. Jenny Harding's projects enabled her to locate herself both as a partner on a number of community led initiatives and, in her teaching role, equip and support students in their roles as 'insider' experts and coproducers of their own community histories.

These locations and relationships have not been without their tensions. Community-based oral history projects run the risk of essentialising the very publics they seek to serve by the act of predefining them as 'communities'. This possibility is more rather than less likely when funding is targeted at such groups e.g. in the case of refugees. Under those circumstances, it is much harder to reflect more openly and critically and develop a more complex understanding of both individual and collective identities. In this sense the process of empowerment cannot be seen as an inevitable or irreversible feature of oral history but understood in rather more chequered terms, with gains here and setbacks there. Another area of recurrent debate amongst oral historians is the assumption that life histories are simply there to be told, spontaneously produced at the touch of a recording button and reproduced in a linear fashion from earliest memories up to the present time. There is a need to respect such viewpoints whilst at the same time question them, thereby fostering a more reflective approach to questions of memory, representation and the contextual aspects of the interview process itself.

The strengths associated with CWASU's capacity to work in the spaces between all four sociologies enables the Unit to address these diverse audiences. However, the potential flaw in this approach is the risk of never wholly satisfying any of them. The metaphor used by Liz Kelly, that of dancing, to capture the relationships established with these groups, that is of slow ponderous missteps or where it is hard to keep pace, chimes with the politics of oral history projects discussed above. It is a process that neither progresses inevitably or stands still; it moves but its direction is never guaranteed. In applied ethics teaching, a key issue is that of reconciling difference. This may take the form of a difference between a personal ethical standpoint taken by the student and those values inscribed in the public healthcare system. Or it may take the form of ethical differences amongst the student body which calls for both negotiation across such viewpoints, whilst at the same time ensuring that it is the reflective process rather than outcome that remains the primary objective.

Whilst in all three instances the overriding aim is transformative, the evidence for this is both patchy and often anecdotal and again by no means axiomatic. Alya Khan's teaching is predicated on a certain kind of pedagogy, that of creating a public through shared enquiry. It is a process that presupposes a consensus with regard to the form but no requirement for such with regard to either content or outcome. On the contrary, the principle of mutual recognition across difference is more important than arriving at the same ethical position. It is precisely this process that disrupts old hierarchies of knowledge and truth, just as the subaltern knowledges produced through community oral history projects and the evidence based research challenges old orthodoxies regarding violence against women and stereotypes, mis-information or simply the absence of knowledge surrounding marginalized communities. In all three cases the focus on critical, reflexive reasoning, understanding both the individual and collective, is what fuels 
transformation. Each has its own techniques. In CWASU's case it is via the research process which provides unique opportunities to reflect and re-appraise. In health ethics classes it takes the form of role plays and group discussions of case studies drawing on the concepts and theoretical traditions of applied ethics. In oral history projects, what is at stake is the historical canon and well established paradigms of doing historical research. The practice of oral history both adds to the canon whilst challenging historiographical orthodoxies (e.g. what counts as an authoritative source). Therein lies its transformative potential.

The willingness of public sociology to work with media and cultural forms outside of the academy and more conventional academic outputs, is evident to a greater or lesser extent in all three case studies and certainly the intention is to extend their reach beyond the confines of the university. Life histories became the focus of local and national exhibitions, of a local play with built in audience participation, of videos, websites, CD Roms as well as the archives of tapes and transcripts themselves. CWASU have also engaged with publics via a range of non conventional fora for example, NGO conferences; campaign organisations; the legal system (as expert witnesses) and public media broadcasts- from documentary dramas to news programmes.

Alongside the more abstract notions of transformation, there are a more tangible set of measures by which such sociological practices have been deemed worthy. These include traditional student feedback evaluations as well as formal project evaluation reports and those relating to particular outputs e.g exhibitions. Whilst the risks alluded to above with regard to CWASU remain, the Unit has successfully built and maintained its reputation across all four arenas.

To conclude, this article has sought to characterise both some of the issues surrounding and possibilities of doing public sociology. The latter has been conceived not so much as one of four sociological quadrants but more situated in the spaces in between. A key feature of this has been the process of public engagement. Alya Khan refers to this as a form of Socratic dialoguing; an iterative process between researchers, policy makers and the many 'publics' comprising civil society. It is pertinent to recall Liz Kelly's reference to feminist research practice for it is the emphasis on practice that characterises public sociology as discussed in each of the three case studies. Bound up with this is a critical approach which we have associated more with a reflective process than with reference to a particular set of values. The process is political with a small 'p' and public sociology can be as much about tactics as about content. As Liz Kelly reminds us there are times when you just let the evidence speak for itself rather than laying it on with an ideological trowel. At other times, no doubt, a trowel is a more appropriate tool: the reflexive and the instrumental thus go hand in hand. The key to an understanding of 'critical' sociology in this context is the need for openness both with regard to evidence and to the experiences of those with whom public sociology seeks to engage. The result is a continuous process of making and re-making the sociological imagination. The recurrent and residual risk, however, in this exciting pursuit of public sociology, is that we end up redefining its boundaries and thus limiting the possibilities for conceptual renewal and social change. 


\section{References}

Barlow, A. (2007). Collaborations for social justice: professionals, publics and policy change. Plymouth, UK: Rowman and Littlefield.

Burawoy, M. (2005). Amercian Sociological Review, 70(1), 4-28.

Burawoy, M. (2008). What might we mean by pedagogy of public sociology? Address to C-SAP Annual Conference, Cardiff, Nov.

Burton, S., Regan, L., \& Kelly, L. (1998). Supporting women and challenging men: lessons from the domestic violence intervention project. Bristol: Policy Press.

Clawson, D., et al. (eds). (2007). Public sociology. London: University of California.

Day, A., Harding, J., \& Mullen, J. (2008). Refugee stories: the refugee communities history project, partnership and collaboration. In H.-L. Skartveit \& K. Goodnow (Eds.), Museums and refugees: new media, play and participation. Paris: UNESCO.

Gabriel, J. (2008). Refugee community oral histories: issues in pedagogy and curriculum development. Teaching in Higher Education, 13(3), 265-278.

Harding, J. (2002). Talking about homelessness: a teaching and research initiative in East London. Teaching in Higher Education, 7(1), 81-95.

Harding, J. (2006). Questioning the subject in biographical interviewing. Sociological Research Online, 11(3).

Harding, J., \& Gabriel, J. (2004). Communities in the making: pedagogic explorations using oral history. International Studies in the Sociology of Education, 14(3), 185-201.

Hill-Collins, P. (2000). Black feminist thought: knowledge, consciousness and the politics of empowerment (2nd ed.). NY: Routledge.

Hill-Collins, P. (2007). Going public: doing the sociology that had no name. In D. Clawson, et al. (Eds.), Public sociology. London: University of California.

Johnsson, E. (2007). Belonging: voices of London's refugees, summative evaluation report, unpublished.

Kelly, L. (1996). Weasel words: paedophilia and the cycle of abuse. Trouble and Strife, 33, 44-49.

Kelly, C. (2007). Proposed Identity and Values for DASS- A working paper. Unpublished.

Kelly, L., Burton, S., \& Regan, L. (1994). Researching women's lives or studying women's oppression: reflections on debates on feminist research. In M. Maynard \& J. Purvis (Eds.), Researching women's lives from a feminist perspective. London: Taylor and Francis.

Leathwood, C. (2004). A critique of institutional inequalities in higher education. Theory and Research in Education, 2(1), 31-48.

Merry, S. (2006). Human rights and gender violence: translating international law into local justice. University of Chicago Press.

Nuffield Education Seminar. (2006). Social Inequalities of Access to Higher Status Universities in the UK (unpublished paper).

Perks, R., \& Thomson, A. (eds). (1998). The oral history reader. London and New York: Routledge.

Scott, J. (2005). Who will speak, and who will listen? British Journal of Sociology, 56(3), 405-09.

Stanley, L. (1990). Feminist Praxis. London: Routledge.

Stuart, M. (1994). You're a big girl now: subjectivities, feminism and oral history. Oral History. Autumn. 55-63.

Thompson, P. (2000). The voice of the past (3rd ed.). Oxford: Oxford University Press. 